\title{
Diversity of Francisella Species in Environmental Samples from Martha's Vineyard, Massachusetts
}

\author{
Zenda L. Berrada $\cdot$ Sam R. Telford III
}

Received: 9 April 2009 / Accepted: 10 July 2009/Published online: 12 August 2009

(C) The Author(s) 2009. This article is published with open access at Springerlink.com

\begin{abstract}
We determined whether Francisella spp. are present in water, sediment, and soil from an active tularemia natural focus on Martha's Vineyard, Massachusetts, during a multiyear outbreak of pneumonic tularemia. Environmental samples were tested by polymerase chain reaction (PCR) targeting Francisella species 16S rRNA gene and succinate dehydrogenase $A(s d h A)$ sequences; evidence of the agent of tularemia was sought by amplification of Francisella tularensis-specific sequences for the insertion element ISFTu2, 17-kDa protein gene tul4, and the $43-\mathrm{kDa}$ outer membrane protein gene fopA. Evidence of $F$. tularensis subsp. tularensis, the causative agent of the human infections in this outbreak, was not detected from environmental samples despite its active transmission among ticks and animals in the sampling site. Francisella philomiragia was frequently detected from a brackish-water pond using Francisella species PCR targets, and subsequently $F$. philomiragia was isolated from an individual brackish-water sample. Distinct Francisella sp. sequences that are closely related to $F$. tularensis and Francisella novicida were detected from samples collected from the brackish-water pond. We conclude that diverse Francisella spp. are present in the environment where human cases of pneumonic tularemia occur.
\end{abstract}

\section{Introduction}

An outbreak of pneumonic tularemia was reported from the island of Martha's Vineyard, MA, USA in 2000 [6]; this

Z. L. Berrada $\cdot$ S. R. Telford III $(\bowtie)$

Tufts Cummings School of Veterinary Medicine,

200 Westboro Road, Building 20,

North Grafton, MA, USA

e-mail: Sam.Telford@tufts.edu outbreak has since continued, with cases from the island reported annually. In the 8 years of this outbreak, more than 90 tularemia cases have been reported from Martha's Vineyard, of which two thirds presented with pneumonic disease (personal communication, Dr. Bela Matyas, Massachusetts Department of Public Health). This unusual outbreak was preceded by a cluster of pneumonic tularemia cases in 1978 in seven inhabitants of a vacation cottage on the island, as well as five others that were not linked to the cottage [25]. The two pneumonic tularemia outbreaks on Martha's Vineyard emphasize the unique situation on the island as the proportion of pneumonic cases greatly exceeds that generally seen in other endemic regions of the USA. Tularemia in the USA is most commonly associated with an infected tick bite or hunting and skinning of infected mammals (e.g., rabbits, muskrats) and usually manifests as the ulceroglandular or glandular form of the disease [1].

A case-control study prepared by the Centers for Disease Control and Prevention and the Massachusetts Department of Public Health subsequently linked an increased risk of pneumonic tularemia with landscaping activities $(\mathrm{OR}=6.7 ; P=0.04)$ [6]. These findings suggested aerosolization of environmental material contaminated with Francisella tularensis subsp. tularensis (type A), the bacterial pathogen that is responsible for the tularemia cases on Martha's Vineyard based on identification of clinical and animal isolates. Field investigations prompted by the 2000 outbreak, however, failed to detect environmental evidence of this pathogen [6]. Whereas F. tularensis subsp. holarctica (type B) has been isolated or detected from multiple environmental sources, including water and mud, as well as fecal and urine material excreted by infected mammals, it is unclear whether type A has the same capacity for prolonged environmental survivability [3, $4,14-16,19,22]$. The nature of the fomites that serve as 
the basis for pneumonic exposures on Martha's Vineyard remains undescribed.

To determine whether $F$. tularensis type A may accumulate in the environment in a Martha's Vineyard field site where it is intensely enzootic [5, 10, 12], we collected samples from or near permanent fresh and brackish-water body sources and analyzed these samples by polymerase chain reaction (PCR) for evidence of Francisella species. In addition, we described the diversity of Francisella spp. within environmental samples collected from this coastal site.

\section{Materials and Methods}

\section{Study Site}

Martha's Vineyard is a $227-\mathrm{km}^{2}$ island off the coast of Massachusetts, USA. Our field site in the Town of Chilmark has been intensively studied since 2000 , when pneumonic tularemia cases were first reported from the island. This site comprises a known natural focus for the agent of tularemia [10-12]. The site abuts Squibnocket Pond (brackish water) and also contains a permanent freshwater pond. A small freshwater marsh, which often loses standing water during the summer, is also located on the property between the two ponds. The site is an undeveloped and privately owned area of glacial outwash plain (elevation $<5 \mathrm{~m}$ ) with coastal grassland and beach scrub (herbaceous and grassy vegetation). The mean temperature and relative humidity (RH) from May through July are $24.4^{\circ} \mathrm{C}$ and $76.1 \% \mathrm{RH}$ based upon data loggers placed at ground level within the actual sampling site in 2008.

\section{Environmental Samples}

The sampling design was similar to that previously reported during a followed up investigation of possible $F$. tularensispositive air filter samples [2]. Water (100-300 mL) and soil samples were collected in sterile Whirlpak sampling bags (Nasco, Ft. Atkinson, WI, USA), and in some instances also in 50-mL conical tubes (Corning, Corning, NY, USA), from a marsh, a freshwater pond, and a brackish-water pond on our field site. Sediments were also collected with many of the water samples. Sampling was undertaken at approximate monthly intervals from April to September during 2005-2007.

Water samples were prepared for analysis by centrifugation at $600 \times \mathrm{g}$ for $10 \mathrm{~min}$; the supernatants were removed from the pelleted sediment. Supernatants were filtered using $0.22-\mu \mathrm{m}$ cellulose nitrate filters (Whatman, Maidstone, England) and placed in a sampling bag with $10-15 \mathrm{~mL}$ of the filtrate. Filter "washes" were obtained by massaging the filter for several minutes with the filtrate in order to dislodge particulates. Particulates were collected by centrifuging $0.25-1.0 \mathrm{~mL}$ of filter wash material, depending on the amount of particulates, in an Eppendorf $5415 \mathrm{C}$ microcentrifuge (Eppendorf, Westbury, NY, USA) at $8,000 \times g$ for $5 \mathrm{~min}$ and processed as described for other particulate matter (e.g., soil, sediment). All samples and filters were stored at $4^{\circ} \mathrm{C}$ until processed, usually within the month.

\section{DNA Extraction}

DNA was extracted from 0.25 to $0.50 \mathrm{~g}$ of sediments, mud, and soil samples (a lesser amount of material with high organic content (e.g., sediments, mud) was processed than those samples with less organic matter (e.g., sand)) using the UltraClean Soil DNA Isolation Kit (Mo Bio Laboratories, Carlsbad, CA, USA) following the manufacturer's protocol with the exception of the lysis step; the beadbeating time was reduced to $5 \mathrm{~min}$, and a 5 -min incubation at $70^{\circ} \mathrm{C}$ was added to reduce DNA shearing. Extracted DNA was stored at $-20^{\circ} \mathrm{C}$ until analyzed by PCR.

\section{PCR}

Samples were analyzed using previously published Francisella species 16S rRNA gene primers Fr153F.1/Fr1281R.1 [2]. The majority of samples were concurrently tested using F. tularensis-specific nested primer sets targeting the 43kDa Francisella outer membrane protein (fopA) [9]. To ensure that the extracted sample content was not inhibitory to PCR, a primer set that broadly amplifies bacterial $16 \mathrm{~S}$ rRNA gene was used in parallel. The set was designated 16SN and had been designed using Primer Express v2.0 (Applied Biosystems, Foster City, CA, USA; 16SN-forward (5'-CCAAAGAATAAGCACCGGCTA) and 16SN-reverse (5'- AATCCTGTTGATCCCCACG)). Samples that displayed inhibition were tested at a 1:10 dilution in PCRgrade water; if inhibition persisted, template was diluted to 1:100 in PCR-grade water and retested. Multiple extractions were performed on many of the collected water samples (e.g., on postcentrifuged sediments and/or multiple filters); thus, a sample was considered positive if one or more of such DNA extractions were PCR positive.

Samples that produced a Francisella spp. 16S rRNA amplicon (primers Fr153F.1/Fr1281R) were also tested using succinate dehydrogenase $(s d h A)$ and $17-\mathrm{kDa}$ lipoprotein (tul4) genes, an insertion element (ISFtu2), and the fop $A$ target if not tested initially with this set $[2,9,23,26]$. Thermocycling conditions for the primary and secondary nested fop $A$ reactions were as follows: $94^{\circ} \mathrm{C}$ for $5 \mathrm{~min}$, followed by 40 cycles of $94^{\circ} \mathrm{C}$ for $45 \mathrm{~s}, 55^{\circ} \mathrm{C}$ for $45 \mathrm{~s}, 72^{\circ} \mathrm{C}$ for $45 \mathrm{~s}$, and a final extension time of $5 \mathrm{~min}$ at $72^{\circ} \mathrm{C}$. The 
thermocycling conditions for the $s d h A$ PCR assay were $94^{\circ} \mathrm{C}$ for $5 \mathrm{~min}$, followed by 40 cycles of $94^{\circ} \mathrm{C}$ for $30 \mathrm{~s}$, $56^{\circ} \mathrm{C}$ for $45 \mathrm{~s}$, and $72^{\circ} \mathrm{C}$ for $60 \mathrm{~s}$ with the final extension of $72^{\circ} \mathrm{C}$ for $5 \mathrm{~min}$; conditions were the same for the tul4, ISFtu2, 16S rRNA, and 16SN PCR assays with the exception of a $60^{\circ} \mathrm{C}$ annealing temperature.

All PCR assays were performed using MJ Research PTC-200 thermocyclers (Bio-Rad Laboratories, Richmond, CA, USA). Amplicons were generated using $12.5 \mu \mathrm{L}$ of Promega GoGreen Taq 2× Master Mix, $2.0 \mu \mathrm{L}$ DNA (or PCR-grade water for no-template controls (NTC)), $0.5 \mu \mathrm{L}$ molecular-grade bovine serum albumin (10 mg/ml), $0.4 \mu \mathrm{M}$ of forward and reverse primers, and PCR-grade water to a total reaction volume of $25 \mu \mathrm{L}$. Amplification products were separated on a $1.5 \%$ Tris-acetate-EDTA agarose gel and visualized by ethidium bromide. Amplicons submitted for sequencing were excised from the gel and purified using the QIAquick PCR purification kit (Qiagen, Valencia, CA, USA).

In order to minimize the risk of contamination, PCR reactions were prepared in a PCR workstation (Cleanspot, Coy Lab Products, Grass Lake, MI, USA) separated from areas used for DNA extraction, amplification, and PCR product handling. Dedicated equipment was used. Negative (no template) and positive controls using DNA from $F$. tularensis Live Vaccine Strain (BEIR NR-14) were included with each run.

\section{Sequence and Phylogenetic Analysis}

Gel-purified PCR products were sent to the University of Maine DNA Sequencing Facility for sequencing using the amplicon target PCR primers. Sequences were compared to those deposited in GenBank using BLAST analysis. Consensus and single-strand sequences were aligned using GeneDoc Multi-Sequence Alignment Editor and ClustalW2 (EMBL-EBI, Cambridge, UK). Chimera analysis on the $16 \mathrm{~S}$ rRNA gene products were performed using the Bellerophon server with parameters set for HuberHugenholtz correction and a window size of 300 [13]. Phylogenetic trees of representative sequences were constructed using the neighbor-joining Jukes-Cantor algorithm in MEGA (v 4.0) with 500 bootstrap replicates; the trees were condensed with a consensus value cutoff set to $60 \%$.

Culture

A subset of samples that tested PCR-positive using the fop $A$ primers were subsequently cultured on cysteine heart agar (CHA; Difco, Becton Dickinson, Sparks, MD, USA) supplemented with 9\% sheep blood (Lampire, Coopersburg, PA, USA). Samples that were cultured from 2007 were inoculated onto selective $\mathrm{CHAB}$ as described by
Petersen et al. [21] but without the addition of $2.5 \mathrm{mg} / \mathrm{mL}$ of amphotericin. The inoculated $\mathrm{CHAB}$ plates were incubated at $37^{\circ} \mathrm{C}$ overnight or until growth was observed, and colonies that were morphologically consistent with Francisella spp. [18, 24] were picked and subcultured onto a new CHAB plate. Afterwards, the loop was placed in $50-\mu \mathrm{L}$ PCR-grade water to wash off residual bacterial cells and boiled at $100^{\circ} \mathrm{C}$ for $5-10 \mathrm{~min}$.

\section{Nucleotide Sequence Accession Numbers}

Sequences analyzed in this study were deposited into GenBank. GenBank accession numbers for $16 \mathrm{~S}$ rDNA sequences are EU503153 to EU503168 and EU492359. Accession numbers for $s d h A$ sequences are EU492352 to EU492358. Accession numbers for tul4 sequences are FJ360762 to FJ360765, and accession numbers for fop $A$ sequences are FJ394026 to FJ394028.

\section{Results}

Francisella Species Detected in Environmental Samples by PCR

To determine whether Francisella spp. were present in the environment in a site where $F$. tularensis type A was intensely enzootic, we analyzed water and soil samples by PCR (Table 1). All samples collected from and around the freshwater pond $(n=19)$ and the marsh from our field site $(n=54)$ tested negative for the Francisella spp. 16S rRNA gene target. Of 83 samples from the brackish-water pond, 23 were positive for the Francisella spp. 16S rRNA gene target. Of the 23 samples that contained Francisella spp. $16 \mathrm{~S}$ rRNA target, 16 were also positive for $s d h A$ and 15 were fop $A$-positive, primarily from the water filter samples. All fop $A$-positive samples, as well as three additional fop $A$ negative samples, were also ISFTu2 PCR positive $(n=23)$. Of the $2316 \mathrm{~S}$ rRNA gene-positive samples, 14 were tul4 positive.

Multiple Francisella Species Identified by Sequence Analysis

16S rRNA gene sequences from 13 samples, including that from an isolate derived from the brackish-water pond, were identified as Francisella philomiragia. These sequences were $99-100 \%$ identical to $F$. philomiragia sequences available in GenBank, with the exception of one amplicon (extraction MB33) that aligned more closely to $F$. philomiragia subsp. noatunensis (previously referred to as $F$. piscicida (AM403242), a fish pathogen). In one sample (extraction MB 89), the 16S rRNA gene sequence obtained 
Table 1 PCR results

\begin{tabular}{|c|c|c|c|c|c|c|}
\hline \multirow{3}{*}{ Sample location } & \multirow{3}{*}{ No. of samples tested } & \multicolumn{5}{|l|}{ PCR results } \\
\hline & & \multirow[t]{2}{*}{ 16s rRNA } & \multirow[t]{2}{*}{$s d h A$} & \multicolumn{3}{|c|}{ F. tularensis specific } \\
\hline & & & & fopA & ISFTu 2 & tul4 \\
\hline Field site marsh & 54 & $\mathbf{0}$ & nt & $\mathbf{0}$ & nt & nt \\
\hline Water (filter or pellet) & 25 & 0 & & 0 & & \\
\hline Soil/sediment/sand & 29 & 0 & & 0 & & \\
\hline Squibnocket pond (brackish water) & 83 & 23 & 16 & 15 & 19 & 14 \\
\hline Water (filter or pellet) & 42 & 19 & 14 & 12 & 16 & 12 \\
\hline Soil/sediment/sand & 41 & 4 & 2 & 3 & 3 & 2 \\
\hline Middle pond (freshwater) & 19 & $\mathbf{0}$ & nt & $\mathbf{0}$ & nt & nt \\
\hline Water (filter or pellet) & 10 & 0 & & 0 & & \\
\hline Soil/sediment/sand & 9 & 0 & & 0 & & \\
\hline
\end{tabular}

$n t$ not tested

clustered with $F$. tularensis species (99\% similarity, 1,098/ 1,100 nucleotides) and groups with sequence from a Francisella novicida clone, but there were not enough differences for a definitive identification based on the phylogenetic analysis (Fig. 1). There were no chimeras detected from the 16S rRNA gene sequences using the Bellerophon analysis [13].

$S d h A$ consensus sequences were obtained from seven environmental samples; phylogenetic analysis of sequences revealed that these samples contain DNA that is similar to that of Francisella spp. previously identified from environmental samples, with $96-99 \%$ similarity to Francisella spp. in GenBank. These environmental samples cluster together and are distinct from other Francisella species in the phylogenetic analysis (Fig. 2).

BLAST results of consensus sequences the ISFTu2 amplicons $(n=5)$ were between $97 \%$ and $100 \%$ similar to F. tularensis sequences. Sequences obtained for the tul4 gene target $(n=4)$ were $95-97 \%$ identical to $F$. tularensis sequences in GenBank while results for fop $A(n=3)$ sequences were more closely identified with $F$. tularensis subsp. holarctica and F. novicida (99-100\%). Even with sequences from these three targets, we cannot assign a more specific identity to the agent or agents that are present in our environmental samples other than to genus Francisella.

\section{Isolation of Francisella philomiragia Species by Culture}

Three initial fopA-positive samples were cultured on CHAB (2005), and five were inoculated onto selective CHAB (2007). Cultures were checked at 24 and $48 \mathrm{~h}$; any cultures that were not overgrown with indigenous bacteria or fungi were checked daily thereafter. F. philomiragia was isolated from a brackish-water sample, sample number 080107-14, by directly culturing filter wash material onto selective
CHAB. No other Francisella sp. was recovered from direct cultures of environmental material that tested positive by $\mathrm{PCR}$, indicating that either nonculturable bacteria were present or other indigenous bacteria overgrew potentially culturable bacteria from these samples.

\section{Discussion}

We sought to detect evidence of environmental $F$. tularensis and other Francisella spp. from a site on the island with known intense enzootic $F$. tularensis type A activity in dog tick and mammal populations $[5,10,12] . F$. tularensisinfected ticks have been found each year from 2001 to 2007 within $50 \mathrm{~m}$ of the brackish-water pond and marsh that were sampled. The pond and marsh receive water runoff via sloughs from a large portion of our study site, including the 290-m-diameter tularemia microfocus [12] and thus would be likely to have $F$. tularensis from carcasses (or other fomites) deposited within. Our failure to detect $F$. tularensis in the pond or marsh could be explained by the bacteria failing to be washed into such bodies of water from surrounding habitat, instability of the bacterium in water or soil, an artifact of our sampling, or a combination of these factors.

Our sampling focused around water sources because $F$. tularensis type $\mathrm{B}$ has previously been recovered from streams and ponds during tularemia epizootics in wildlife populations [14-16, 19]; much of the suggested environmental stability attributes (survival within soil or water) of type A are inferred from studies of type B as opposed to having been directly demonstrated. In order to increase the cumulative volume of material tested, numerous samples were collected at the various collection points around the water bodies. The sample volume varied based on the 
Figure 1 Phylogenetic tree of $16 \mathrm{~S}$ rDNA sequences. Neighbor-joining analysis was done using Jukes-Cantor parameters and 500 bootstrap replicates; tree was condensed to show consensus values $>60 \%$.

The boxed groups represent those clades which include sequences from the brackishwater pond. DNA extraction designation and GenBank accession numbers follow the sample name. Reference sequences are designated as follows: Ftt, F. tularensis subsp. tularensis; Fth, F. tularensis subsp. holarctica; Ftmed, F. tularensis subsp. mediasiatica; Fnov, F. novicida; Fpisc, F. piscicida; UPBclone, uncultured proteobacteria clone; Fphil, F. philomiragia; FrancSp, Francisella species clinical isolates; and Franc endosymbiont, Francisella endosymbiont from the tick, Dermacentor variabilis

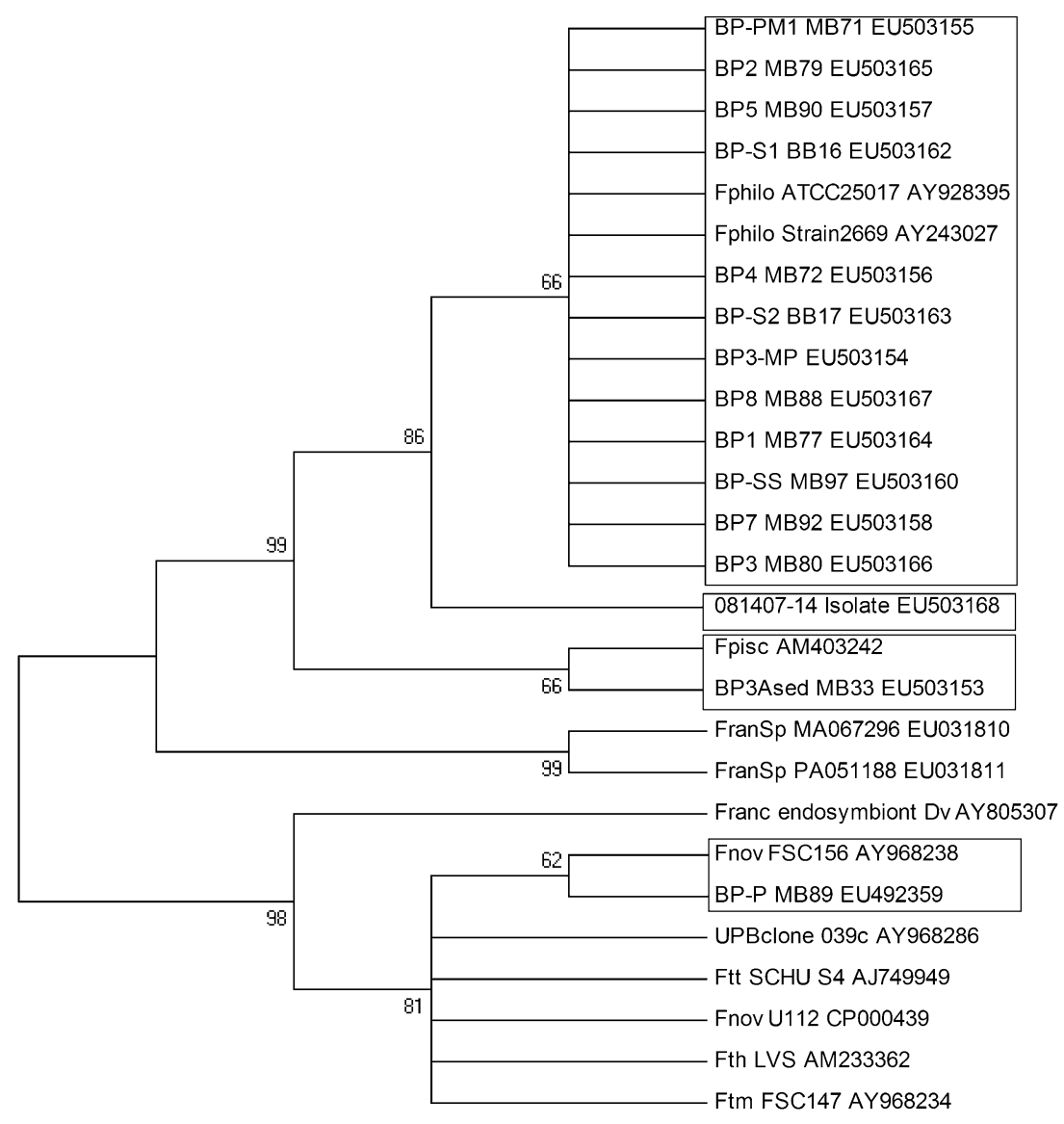

condition of the water body at the time of collection (e.g., water level, heavy plant/organic content) as this affected downstream processing (e.g., filtration, DNA extraction).

The use of molecular methods such as PCR to analyze natural water sources and soil samples for the presence of $F$. tularensis has been previously documented [2, 8, 29]. Consistent with the approach of these published reports, we utilized broad-range primers targeting the Francisella species $16 \mathrm{~S}$ rRNA gene and $s d h A$ gene and a battery of additional previously published $F$. tularensis-specific primers (tul4, ISFtu2, and fopA) to analyze environmental samples for the presence of Francisella spp. We expected all 23 of the Francisella sp. 16S rRNA gene-positive samples to also be positive for the $s d h A$ gene target; however, we found that only 16 of these samples were positive. Interestingly, concordance was better when comparing the $s d h A$ gene target and the presumptively $F$. tularensis-specific PCR assays; of the $s d h A$-positive samples, 14 were fop $A$ positive (nested PCR) and tul4 positive. There were more ISFtu 2 positives than $s d h A$ positives $(n=$ 19); however, the former primer set is more sensitive than the latter due to the presence of multiple insertion sequence elements in characterized F. tularensis genomes [27]. Potential factors, such as low concentration of target DNA and/or complex environmental media background in which
DNA was extracted, may have affected the overall concordance between the Francisella sp.-specific PCR assays. We also cannot discount the possibility that previously uncharacterized Francisella spp. in the environment may not be amplified by the primers used in our study because of differences at the priming sites.

Sequencing and phylogenetic analysis of the $16 \mathrm{~S}$ rRNA gene PCR products identified $F$. philomiragia as the predominant Francisella sp. in PCR-positive environmental samples taken from the brackish-water pond. This is not an unexpected finding; many human infections with $F$. philomiragia are seawater-derived [28], and F. philomiragia subsp. noatunensis (proposed $F$. noatunensis comb. nov) and other closely related Francisella sp. (i.e. F. piscicida, proposed $F$. noatunensis comb. nov.) are fish pathogens that included several oceanic species [18]. We obtained one $16 \mathrm{~S}$ rRNA gene product (extract MB 89) that was not identified as $F$. philomiragia; this sequence was 99\% identical to known $F$. tularensis subspecies and phylogenetically grouped more closely with $F$. novicida sequences in GenBank (Fig. 1). F. novicida is commonly associated with brackish-water environments and, while a definitive identification could not be made from this sequence, it is likely that the organism from which this sequence derived is a $F$. novicida-like bacterium. Although 
Figure 2 Phylogenetic tree of $s d h A$ sequences. Neighborjoining analysis was done using Jukes-Cantor parameters and 500 bootstrap replicates; tree was condensed to show consensus values $>60 \%$. The boxed groups represent those clades which include sequences from the brackish-water pond. DNA extraction designation and gene GenBank accession numbers follow the sample name. Reference sequences are designated as follows: Ftt, F. tularensis subsp. tularensis; Fth, F. tularensis subsp. holarctica; Ftm, F. tularensis subsp. mediasiatica; Fnov, F. novicida; UPBclone, uncultured proteobacteria clone; Fphil, F. philomiragia; and FrancSp, Francisella species from clinical isolates

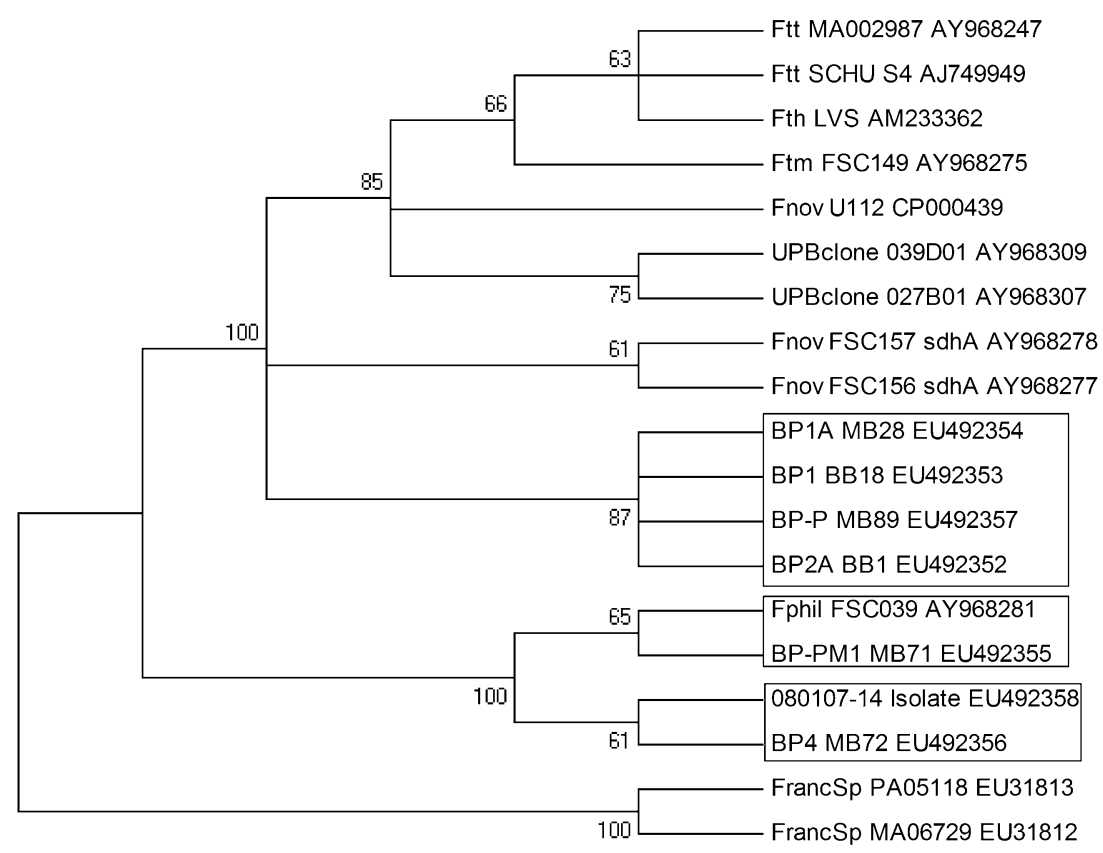

F. philomiragia sequences were frequently obtained from 16S rRNA gene-positive samples, BLAST results and phylogenetic analysis for most of the $s d h A$ sequences obtained from the same samples were not identified as $F$. philomiragia, suggesting that multiple Francisella spp. may be simultaneously present in the samples. The $s d h A$ sequences are clearly that of previously uncharacterized Francisella sp. and cluster together in their own distinct clade (Fig. 2), and the presence of identical sequences in multiple samples suggests that the sequences are not the result of random chimeric formation during the PCR process. As with the $s d h A$ gene target sequences, phylogenetic analyses of sequences obtained from a subset of positive samples for the nested fopA and tul4 gene targets also show that these environmental samples contain DNA from a species that is closely related to known $F$. tularensis subspecies but again cluster together in a separate clade (data not shown).

Further molecular characterization of the Francisella spp. detected in these environmental samples would be facilitated by isolation of the bacteria that DNA sequences were obtained; however, attempts to isolate these bacteria of interest were generally unsuccessful. Although methods have been proposed for enhancing the possibility of directly culturing $F$. tularensis from heavily contaminated tissues onto appropriate laboratory media such as CHABcontaining antibiotics [21], our personal observation is that direct culture of environmental samples for the purpose of isolating F. tularensis (or F. tularensis-like organisms) is challenging given the probability of nontarget overgrowth during the prolonged incubation which is sometimes required to culture F. tularensis on laboratory media [24].
New selective CHAB medium that effectively reduces the growth of environmental microflora, thereby allowing the isolation of Francisella spp. from seawater [20], will undoubtedly be useful for future environmental studies. Further challenges to the isolation of Francisella spp. from these complex samples are that bacteria may exist in a viable but nonculturable state [7] or that novel Francisella spp. may have special laboratory media requirements that preclude cultivation on CHAB. It is possible that isolation of F. tularensis or other Francisella spp. may have been more successful by utilizing animal inoculation in a susceptible animal model (e.g., mouse, guinea pig). Earlier studies by Jellison et al. relied on the use of guinea pigs for recovery of $F$. tularensis (subspecies not reported) from freshwater and mud samples from streams at which tularemia epizootics were occurring in beavers (Castor canadensis) $[15,19]$.

Although we did not detect $F$. tularensis type A in our environmental samples, we detected other Francisella spp. sequences from these samples, demonstrating the efficacy of our sampling protocol and analysis. Our data and that of others demonstrate that the "F. tularensis-specific" primer sets (fopA, tul4) amplify DNA from bacteria other than the agent of tularemia (F. tularensis subsp. tularensis, $F$. tularensis subsp. holarctica) and should be used with caution with environmental samples taken for outbreak investigation. [2]. Diverse Francisella spp., including two distinct Francisella tick endosymbionts [11], F. philomiragia, $F$. novicida-like bacteria, and $F$. tularensis-like environmental bacteria all coexist in our study site with the agent of tularemia, F. tularensis type A. It is likely that other sites that are enzootic or epizootic for tularemia might 
contain similar diversity. The recent isolation of two novel strains of Francisella sp. from clinical samples, in which at least one case was possibly associated with a coastal environment, suggests that diverse Francisella spp. may be human pathogens (particularly for immunocompromised individuals) [17] and highlights the utility of environmental sampling to provide information about the prevalence of known and yet uncharacterized Francisella and their potential interactions.

Acknowledgements This paper is a portion of a thesis submitted by ZLB in partial fulfillment of the requirements for the Ph.D. in comparative biomedical sciences at Tufts University. We thank Heidi Goethert for her assistance with phylogenetic analysis. We also thank John Varkonda of the Massachusetts Department of Conservation and Recreation for logistical support, the Vineyard Open Land Foundation for access to study sites, and many other individuals and agencies of Martha's Vineyard for facilitating our research. Our work is funded by grants from the National Institutes of Health (R21 AI 053411, RO1 AI 064218, and NO1 AI 30050).

Open Access This article is distributed under the terms of the Creative Commons Attribution Noncommercial License which permits any noncommercial use, distribution, and reproduction in any medium, provided the original author(s) and source are credited.

\section{References}

1. Anonymous (2002) Tularemia-United States 1990-2000. MMWR Morb Mortal Wkly Rep 51:181-184

2. Barns S, Grow C, Okinaka R, Keim P, Kuske C (2005) Detection of diverse new Francisella-like bacteria in environmental samples. Appl Environ Microbiol 71:5494-5500

3. Bell J, Stewart S (1975) Chronic shedding tularemia nephritis in rodents: possible relation to occurrence of Francisella tularensis in lotic waters. J Wildl Dis 11:421

4. Bell J, Stewart S (1983) Quantum differences in oral susceptibility of voles, Microtus pennsylvanicus, to virulent Francisella tularensis type B, in drinking water: implications to epidemiology. Ecol Dis 2:151-155

5. Berrada Z, Goethert H, Telford S 3rd (2006) Raccoons and skunks as sentinels for enzootic tularemia. Emerg Infect Dis 12:1019-1020

6. Feldman K, Enscore R, Lathrop S, Matyas B, McGill M, Schriefer M, Stiles-Enos D, Dennis D, Petersen L, Hayes E (2001) An outbreak of primary pneumonic tularemia on Martha's Vineyard. N Engl J Med 345:1601-1606

7. Forsman M, Henningson E, Larsson E, Johansson T, Sandstrom G (2000) Francisella tularensis does not manifest virulence in viable but non-culturable state. FEMS Microbiol Ecol 31:217-224

8. Forsman M, Nyren A, Sjostedt A, Sjokvist L, Sandstrom G (1995) Identification of Francisella tularensis in natural water samples by PCR. FEMS Microbiol Ecol 16:83-92

9. Fulop M, Leslie D, Titball R (1996) A rapid, highly sensitive method for the detection of Francisella tularensis in clinical samples using the polymerase chain reaction. Am J Trop Med Hyg 54:364-366

10. Goethert H, Shani I, Telford S 3 rd (2004) Genotypic diversity of Francisella tularensis infecting Dermacentor variabilis ticks on Martha's Vineyard, Massachusetts. J Clin Microbiol 42:4968-4973
11. Goethert H, Telford S 3rd (2005) A new Francisella (Beggiatiales: Francisellaceae) inquiline within Dermacentor variabilis say (Acari: Ixodidae). J Med Entomol 42:502-505

12. Goethert H, Telford S 3rd (2009) Nonrandom distribution of vector ticks (Dermacentor variabilis) infected by Francisella tularensis. PLoS Path 5:1-7

13. Huber T, Faulkner G, Hugenholtz P (2004) Bellerophon; a program to detect chimeric sequences in multiple sequence alignments. Bioinformatics 20:2317-2319

14. Jellison W, Epler D, Kuhns E, Kohls G (1950) Tularemia in man from a domestic rural water supply. Public Health Rep 50:219226

15. Jellison W, Kohls G, Butler W, Weaver J (1942) Epizootic tularemia in the beaver, Castor Canadensis, and the contamination of stream water with Pasteurella tularensis. Am J Hyg 36:168182

16. Karpoff S, Antonoff N (1936) The spread of tularemia through water, as a new factor in its epidemiology. J Bacteriol 32:243-258

17. Kugeler K, Mead P, McGowan K, Burnham J, Hogarty M, Ruchelli E, Pollard K, Husband B et al (2008) Isolation and characterization of a novel Francisella sp. from human cerebrospinal fluid and blood. J Clin Microbiol 46:2428-2431

18. Ottem K, Nylund A, Karlsbakk E, Friis-Møller A, Kamaishi T (2009) Elevation of Francisella philomiragia subsp. noatunensis Mikalsen et al. (2007) to Francisella noatunensis comb. nov. [syn. Francisella piscicida Ottem et al. (2008) syn. nov.] and characterization of Francisella noatunensis subsp. orientalis subsp. nov., two important fish pathogens. J Appl Microbiol 106:1231-1243

19. Parker R, Steinhaus E, Kohls G, Jellison W (1951) Contamination of natural waters and mud with Pasteurella tularensis and tularemia in beavers and muskrats in the Northwestern United States. Natl Inst Health Bull 193:1-61

20. Petersen J, Carlson J, Yockey B, Pillai S, Kuske C, Garbalena G, Pottumarthy S, Chalcraft L (2009) Direct isolation of Francisella spp. from environmental samples. Lett Appl Microbiol 48:663-667

21. Petersen J, Schriefer M, Gage K, Montenieri J, Carter L, Stanley M, Chu MC (2004) Methods for enhanced culture recovery of Francisella tularensis. Appl Environ Microbiol 70:3733-3735

22. Reintjes R, Dedushaj I, Gjini A, Jorgensen T, Cotter B, Lieftucht A, D'Ancona F, Dennis D et al (2002) Tularemia outbreak investigation in Kosovo: case control and environmental studies. Emerg Infect Dis 8:69-73

23. Sjostedt A, Eriksson U, Berglund L, Tarnvik A (1997) Detection of Francisella tularensis in ulcers of patients with tularemia by PCR. J Clin Microbiol 35:1045-1048

24. Tarnvik A, Chu M (2007) New approaches to diagnosis and therapy of tularemia. Ann N Y Acad Sci 1105:378-404

25. Teutsch SM, Martone WJ, Brink EW, Potter M, Eliot G, Hoxsie R, Craven R, Kaufmann A (1979) Pneumonic tularemia on Martha's Vineyard. N Engl J Med 301:826-828

26. Thomas R, Johansson A, Neeson B, Isherwood K, Sjostedt A, Ellis J, Titball R (2003) Discrimination of human pathogenic subspecies of Francisella tularensis by using restriction fragment length polymorphism. J Clin Microbiol 41:50-57

27. Titball R, Petrosino J (2007) Francisella genomics and proteomics. Ann N Y Acad Sci 1105:98-121

28. Wenger J, Hollis D, Weaver R, Baker C, Brown G, Brenner D, Broome C (1989) Infection caused by Francisella philomiragia (formerly Yersinia philomiragia). A newly recognized human pathogen. Ann Intern Med 110:888-892

29. Whitehouse C, Hottel H (2007) Comparison of five commercial DNA extraction kits for the recovery of Francisella tularensis DNA from spiked soil samples. Mol Cell Probes 21:92-96 